3. Copley, A. L. Rheol. Acta 1, 663, 1961.

4. Copley, A. L. and Scott Blair, G. W. Proc. 8th Int. Cong. Blood Transfusion, Tokyo, 1960, p. 6. Basel: S. Karger, Basel 1962.

5. Ruhenstroth-Bauer, C., Brittinger, G., Granzer, E. and Nass, G. Deutsche med. Wchnschr. 85, 808, 1960.

6. Gomulkiewicz, J. Studia Biophysica 35, 21, 1973.

7. Boyd, J. J. M. and Sanderson, J. J. Plasma Dynamics. Barnes and Noble, New York, 1969.

8. Cutler, J. W. Am. J. med. Sci. 183, 643, 1932.

9. Reichel, H. Blutkörperchensenkung., Springer-Verlag, Vienna, 1936.

10. Westergren, A. Acta med. Scand. 54, 247, 1920-1921.

11. Whelan, J. A., Huang, C. R. and Copley, A. L. Biorheology 7, 205, 1971.

12. Huang, C. R., Whelan, J. A., Wang, H. H. and Copley, A. L. Biorheology 8, 157, 1971.

13. Copley, A. L., Huang, C. R. and King, R. G. Biorheology 10, 17, 1973.

14. Huang, C. R., King, R. G. and Copley, A. L. Biorheology 10, 23, 1973.

15. Copley, A. L., Huang, C. R. and King, R. G. Symposium XI: Biorheology, IV. Int. Biophys. Cong. Moscow, 1973 , p. 438. Pushchino, Academy of Sciences of the U.S.S.R., 1973.

16. Copley, A. L., King, R. G., Chien, S., Usami, S., Skalak, R. and Huang, C. R. Biorheology 12, $257,1975$.

17. Copley, A. L., Luchini, B. W. and Whelan, E. W. In: Hemorheology (Edited by Copley A. L.), p. 375. Pergamon Press, Oxford, 1968.

18. Knisely, M. H. Postgrad. Med. 10, 15, 1951.

19. Fåhraeus, R. Rheol. Acta 1, 656, 1961.

20. Copley, A. L. Rheol. Acta 1, 663, 1961

21. Leeuwenhoek, A. van (spelled Lewenhoek in the original paper), Phil. Trans. R. Soc., Lond. 22, 447, 1700.

\title{
APPENDIX
}

\section{A MATHEMATICAL INTERPRETATION OF THE PARAMETERS AFFECTING ERYTHROCYTE SEDIMENTATION}

\author{
SYOTEN OKA \\ Kyorin University School of Medicine, Mitaka, Tokyo, Japan
}

Let the erythrocyte sedimentation rate be denoted by $v$. The erythrocyte or an aggregate of erythrocytes is sedimented at a constant velocity $v$ in blood. Two forces are acting on the particle. The one is given by $\left(m-m_{0}\right) g$, where $m$ is the mass of the particle, $m_{0}$ is the mass of plasma excluded by the particle, and $g$ is the acceleration of gravity. The term $m_{0} g$ indicates that the effect of buoyancy is taken into account.

The other force is the drag $F$ due to the viscosity of blood. The drag is proportional to $v$, that is,

$$
F=f v,
$$

where $f$ is the frictional constant.

Since the particle is sedimented at a constant velocity, the above two forces must balance:

$$
f v=\left(m-m_{0}\right) g,
$$

or

$$
v=\frac{\left(m-m_{0}\right) g}{f}
$$

Let us assume, for simplicity, that the particle is a sphere of radius $r$. Then we have from Stokes' equation

$$
f=6 \pi r \eta
$$

where $\eta$ is the viscosity of blood. Here the viscosity of plasma $\eta_{0}$ should not be used, because the $\operatorname{drag} F$ is influenced by the existence of other particles.

On the other hand, $m$ and $m_{0}$ are written as

$$
m=\frac{4 \pi}{3} r^{3} \rho, \quad m_{0}=\frac{4 \pi}{3} r^{3} \rho_{0}
$$

where $\rho$ and $\rho_{0}$ are the density of the particle and plasma, respectively.

Substitution of equations (2) and (3) into equation (1) gives

$$
v=\frac{2}{9}\left(1-\frac{\rho_{0}}{\rho}\right) \rho g \cdot \frac{r^{2}}{\eta} .
$$

The quantity $\left[1-\left(\rho_{0} / \rho\right)\right]$ is the Archimedes factor.

When the sedimentation occurs in a shear field, the blood viscosity $\eta$ as well as the radius $r$ of the aggregate of the erythrocytes will depend upon the shear rate $\dot{\gamma}$. Equation (4), in the light of the experimental findings, indicates the behavior of $r^{2} / \eta$ as a function of $\dot{\gamma}$. 
For small values of $\dot{\gamma}$, no (or only slight) disaggregation will take place, that is, $r$ is a constant (or nearly constant), while $\eta$ decreases since blood shows shear-thinning behavior. That means increase of ESR with increase in $\gamma\left(0.01-0.1 \mathrm{sec}^{-1}\right)$. For larger values of $\dot{\gamma}\left(0.1-10 \mathrm{sec}^{-1}\right)$, however, disaggregation will take place, that is, $r$ decreases, while $\eta$ decreases to a limiting value with increase in $\dot{\gamma}$. The decrease of ESR may be possible with increase in $\dot{\gamma}$. Hence the curve of ESR shows a maximum.

From equation (4) we have

$$
r \propto \sqrt{ }(\eta v)
$$

Since $\eta$ and $v$ are known quantities of $\dot{\gamma}$ from experimental data, equation (5) gives the size of sedimenting particle as a function of the shear rate $\dot{\gamma}$.

Aggregation and disaggregation, that is the relationship between $r$ and $\dot{\gamma}$ will depend upon the electrostatic repulsion and the van der Waals attraction between the erythrocytes.

In the above theoretical consideration, the erythrocyte as well as the aggregates are assumed to be spherical in shape. However, this is not the case. The erythrocyte is a biconcave disc, and the aggregates form rouleaux or even more complex structures. For such an anisodimensional particle, equation (1) for the frictional constant should be replaced by another formula. However, the above simplified treatment may manifest the general feature of our problem. Further refinement is of course desirable. 